\title{
A Shaking Table Test Design on Seismic Strengthened Brick Masonry Structures
}

\author{
LIU Jie Ping ${ }^{1, a^{*}}$, LIU Chen ${ }^{2, b}$ and ZHANG Ling Xin ${ }^{1, a}$ \\ ${ }^{1}$ Institute of Engineering Mechanics, China Earthquake Administration; Key Laboratory of \\ Earthquake Engineering and Engineering Vibration of China Earthquake Administration, \\ Harbin, Heilongjiang, 150080, China \\ ${ }^{2}$ Tianhua Architecture Planning \& Engineering Limited, Shanghai 200235, China \\ ajieping_liu@126.com, ${ }^{b}$ liu_chen_seu@163.com, ${ }^{C}$ lingxin_zh@126.com
}

\begin{abstract}
Keywords: Externally steel reinforcement mesh mortar layer, Seismic strengthened, Brick masonry structure, Shaking table test.

Abstract. The 1:4 scale model for shaking table test was designed as a typical three-storey-office building strengthened with external steel reinforcement mesh mortar layer. The process of modeling was provided, including the relationship of model and proto structure, and the design principle of model components. The scheme of shaking table test was determined, including simulation of wall vertical compressive stress, the artificial mass, the distribution of test instrument and strain gauge, the selection of ground motions.
\end{abstract}

\section{Introduction}

By the simulated earthquake shaking table test, the ground motion on the whole structure could be simulated, the real seismic response of the structure would be repeated, and meanwhile the rate effect and the influence of the artificial boundary conditions would be eliminated in the pseudo-static test of components. Through the shaking table test, each stage of the structure mechanical properties and damage mechanism would be known, the characteristics of structure failure would be visually observed, and thus structure seismic weak links and failure modes would be determined.

In order to study the integral seismic performance and the seismic strengthening effect of brick masonry buildings strengthened by externally steel reinforcement mesh mortar layer, the 1:4 scale model for shaking table test was designed as a typical three-storey-office building in 1970's as a prototype with references to the earlier seismic code[1,2], and strengthened with external steel reinforcement mesh mortar layer. The first and second floor was strengthened and the third floor was untouched as comparison. The key techniques of the process of modeling were discussed, especially the determination of brick dimension and the co-working of the three different kinds of material, i.e. reinforcement mesh, mortar layer and brick wall. The selection of model material, the determination of similitude relationship, the construction methods of details of seismic measure and reinforcement layer were presented. The realizing way of structural members and the details of seismic measures were described in detail. The scheme of shaking table test was determined, including simulation of wall vertical compressive stress, the artificial mass, the distribution of test instrument and strain gauge, the selection of ground motions and the testing conditions. The post process of shaking table test was discussed for the preparation of the next step of simulated earthquake shaking table test.

\section{Design and manufacture of the model}

\section{Relationship of model and proto structure.}

Limited by shaking table size and bearing capacity, the model selection of the prototype structure of two bay, which is referred to as the model prototype. In the model prototype, there were two outer cross walls, one inner cross wall, two outer longitudinal walls and two inner longitudinal walls in the test. The geometric similarity constant of the model is 0.25 , which is shown as Fig. 1 . In "Regulations 
of buildings aseismic test method" (JGJ101-96), the strength level of the regulation test block masonry structure should be consistent with the prototype structure, so in this test the MU7.5 brick machine was selected. At the same time considering the prototype of mortar strength was low, the initial cracks may be created by the lower strength of mortar in the process of production, transportation, so the model mortar was selected by M1.0 which was same as the mortar of prototype. Determined by material property, the similitude law of elastic modulus test similar constant was taken by 1.0.

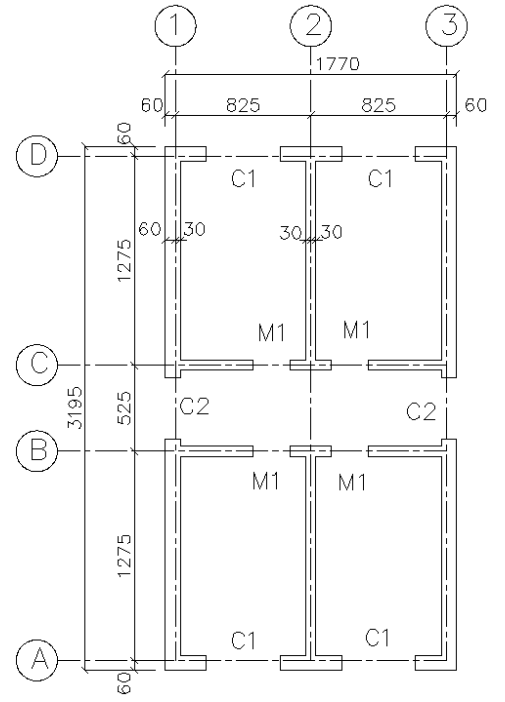

(a) Structural plan

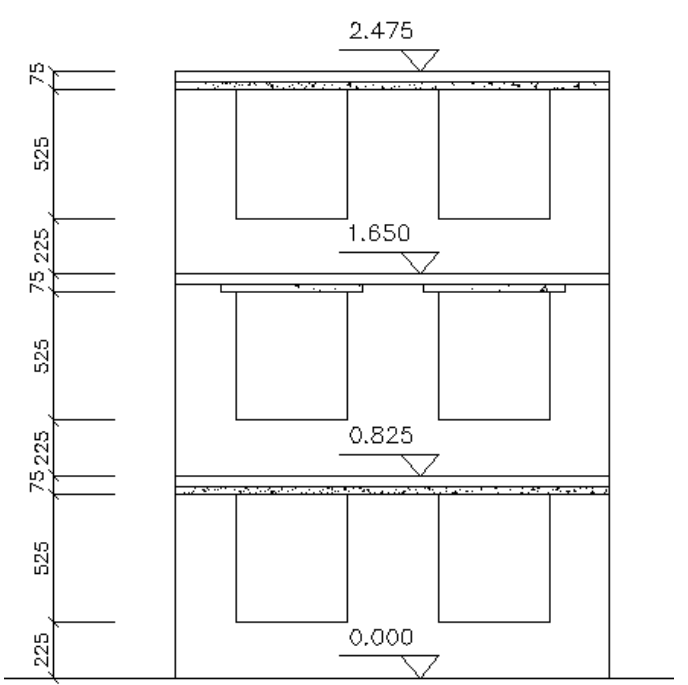

(b) Structural Elevation

Fig. 1 Structural figure of the model

In the design of reduced scale model test, artificial mass is calculated by artificial mass similar rate generally. In the model prototype, the plan dimension is $7.08 \mathrm{~m}^{*} 12.78 \mathrm{~m}$, height is $9.9 \mathrm{~m}$, weight is about 500t. For the capacity limitation of the shaking table,

The prototype test model plane size, building, total structure weighs about $500 \mathrm{t}$, if the human quality, completely model should be the total weight of $32 \mathrm{t}$, beyond the bearing capacity of $30 \mathrm{t}$ vibration table, therefore cannot use artificial quality model completely.On vibration table by using the gravity model, the peak acceleration and requires a high degree of effective bandwidth, at the same time for masonry structure model test, ignore the gravity model of vertical compressive stress leads to the deficiency of the component failure state changes. Therefore, this experiment adopts owe human quality model, on the basis of the existing similitude law, according to the vibration table consistency similar ratio is used to determine the bearing capacity and other physical quantities of similar constant.

Design principle of model components. The geometric similarity constant of the model was determined by 0.25 and the elastic modulus similar constant was 1.0. Combined with the mechanical performance of componts and the experiment theory, the design principle of each component was determined.

(1) Wall. The prototype wall material was used, i.e. MU7.5 brick made by machine and mechanism and M1.0 mixed mortar, the model brick masonry was used. The principle of the test model brick size was, the geometric similarity ratio in the width direction was 1:4, and in thickness direction was 1:2. When the masonry wall was built, the horizontal mortar joint thickness should be within $3 \sim 5 \mathrm{~mm}$. According to YiShun yiding way, the Masonry model walls with the thickness of $60 \mathrm{~mm}$ and $90 \mathrm{~mm}$ were built to simulate the wall of the proto sturcture with the thickness of $240 \mathrm{~mm}$ and $370 \mathrm{~mm}$. According to the code the tie bars should be set in the corners of exterior wall and wall junctions.

(2) Reinforcement layer. In this model test, the externally steel reinforcement mesh mortar layer with $\Phi 6 @ 300$ steel was simulated by galvanized steel wire and the same typ mortar. In the design of model, the geometrical parameters of reinforcement mortar layer determined by similitude law. The reinforcement strengthening belts were located in the ring beam of all walls on second floor, and the four cornor of outer walls and the constructional column position on first and second floor, which the 
space of strengthened steel was half of the original space.

(3) Precast slab. $100 \mathrm{~mm}$ thick slab was used in the prototype structure. Considering the construction convenience and the need of artificial weight, the $40 \mathrm{~mm}$ thick slab was used in model. According to the similarity ratio, the length of precast slab plate end should be adjusted in accordance with the structure of the common size, which is $60 \mathrm{~mm}$ for outer wall and $30 \mathrm{~mm}$ for inner wall.

(4) Ring beam and lintel. The C20 particle concrete was used in the concrete component, such as ing beam and lintel, to simulate the C20 concrete of the prototype, and steel wire was used to simulate the reinforcement in concrete structures. According to the principle of similitude law, the equivalent reinforcement was calculated. The structural measures in other parts of the model, could be determined in accordance with the actual construction requirements and geometric similitude law.

\section{Test scheme}

In the testing scheme, there were the determination of the model artificial mass and similar relationship, testing instruments and the distribution of strain gauge, the selection of ground motion and the determination of input conditions, which is described as follows:

The artificial mass of the model. The lacking artificial mass was used in the shaking table test $[3,4]$, which the eventual artificial mass measure is shown in the Table 1. From the table, it can be seen that, the total mass of model was 27 tons, which was the $83 \%$ of the artificial mass. The differece of the failure mode caused by the lacking mass could be ignored [5].

Table 1 The artificial mass of the model (unit: kN)

\begin{tabular}{|c|c|c|c|c|c|}
\hline Storey & Type of walls & $\begin{array}{l}\text { Number of } \\
\text { walls }\end{array}$ & Artificial mass & $\begin{array}{c}\text { The floor artificial } \\
\text { mass }\end{array}$ & Real weight \\
\hline \multirow[t]{3}{*}{ First } & Outer cross wall & 4 & 8.9 & \multirow{3}{*}{68.0} & \multirow{3}{*}{70} \\
\hline & Inner cross wall & 2 & 9.4 & & \\
\hline & $\begin{array}{l}\text { Inner longitudinal } \\
\text { wall }\end{array}$ & 4 & 3.4 & & \\
\hline \multirow[t]{3}{*}{ Second } & Outer cross wall & 4 & 8.3 & \multirow{3}{*}{63.2} & \multirow{3}{*}{65} \\
\hline & Inner cross wall & 2 & 8.8 & & \\
\hline & $\begin{array}{l}\text { Inner longitudinal } \\
\text { wall }\end{array}$ & 4 & 3.1 & & \\
\hline \multirow[t]{3}{*}{ Third } & Outer cross wall & 4 & 5.4 & \multirow{3}{*}{44.0} & \multirow{3}{*}{60} \\
\hline & Inner cross wall & 2 & 7.2 & & \\
\hline & $\begin{array}{l}\text { Inner longitudinal } \\
\text { wall }\end{array}$ & 4 & 2.0 & & \\
\hline
\end{tabular}

\section{The determination of similitude law.}

Three similar constants were determined in the lacking artificial model, which were the length, elastic modulus and equivalent density. After that the other similar physical constants were calculated by using the general similitude laws. The similar constants of the model are shown in the Table 2 . 
Table 2 The determination of similitude law

\begin{tabular}{cccc}
\hline \multicolumn{2}{c}{ Physical parameters } & Relation & Similar to the constant \\
\hline \multirow{2}{*}{ Geometric } & length & $l_{\mathrm{r}}$ & 0.25 \\
& strain & $\varepsilon_{\mathrm{r}}=\sigma_{\mathrm{r}} / E_{\mathrm{r}}$ & 1.00 \\
Material & Modulus of elasticity & $E_{\mathrm{r}}$ & 1.00 \\
& equivalent density & $\rho_{\mathrm{r}}=M_{\mathrm{r}} / l_{\mathrm{r}}^{3} M_{\mathrm{r}}$ & 3.30 \\
phycics & stress & $\sigma_{\mathrm{r}}=E_{\mathrm{r}}$ & 1.00 \\
& force & $F_{\mathrm{r}}=\sigma_{\mathrm{r}} l_{\mathrm{r}}^{2}$ & 0.0625 \\
\multirow{2}{*}{ Dynamic } & time & $t_{\mathrm{r}}=l_{\mathrm{r}} \sqrt{\rho_{\mathrm{r}}}$ & 0.45 \\
properties & frequency & $\omega_{\mathrm{r}}=\sqrt{1 / \rho_{\mathrm{r}}} / l_{\mathrm{r}}$ & 2.20 \\
& acelerationm & $a_{\mathrm{r}}=1 /\left(l_{\mathrm{r}} \rho_{\mathrm{r}}\right)$ & 1.21 \\
\multicolumn{2}{c}{ Acceleration } & 1.0 & 1.0 \\
\hline \multicolumn{2}{c}{ of gravity } & &
\end{tabular}

\section{Location of sensors.}

In the simulated earthquake shaking table test, the instruments were used, such as displacement sensor, acceleration sensor and strain gauge, etc. Displacement sensors and acceleration sensors were installed on the floor and each floor and roof top surface, which the horizontal wire should be fixed on a steel frame. By displacement sensors the absolute displacement of the floors, including shear, bending and basic composition such as rotation were measured. on each floor and roof arrangement of $\mathrm{X}$ and $\mathrm{Y}$ direction acceleration sensors and displacement sensors were installed, which are shown as in Figure 2. In this figure, displacement sensor are shown by the small triangel, and aceleration sensor are shown by the arrows. The Arrangement of measuring points in the project are shown in Fig. 3, which the total number of strain gauges is 37 .

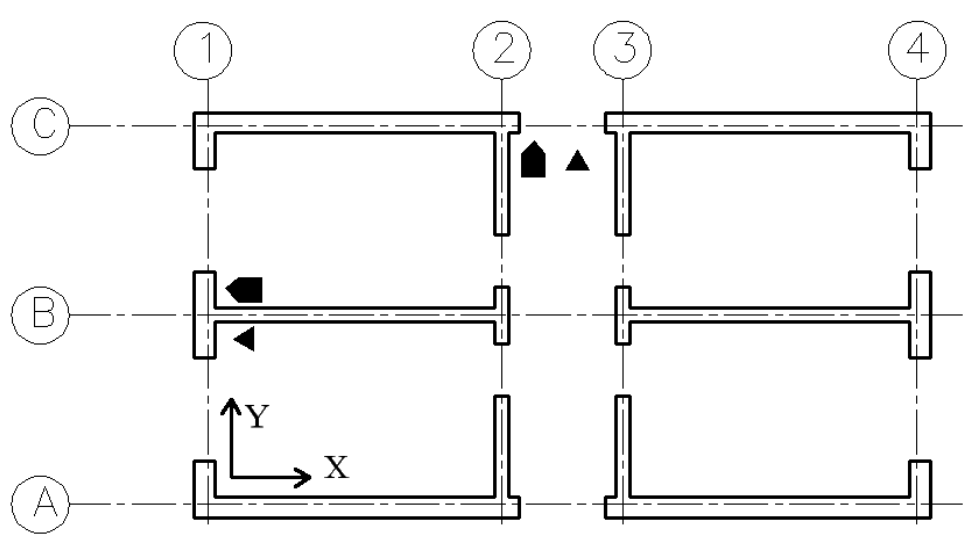

Fig. 2 The plan arrangement of displacement sensors and acceleration sensors 


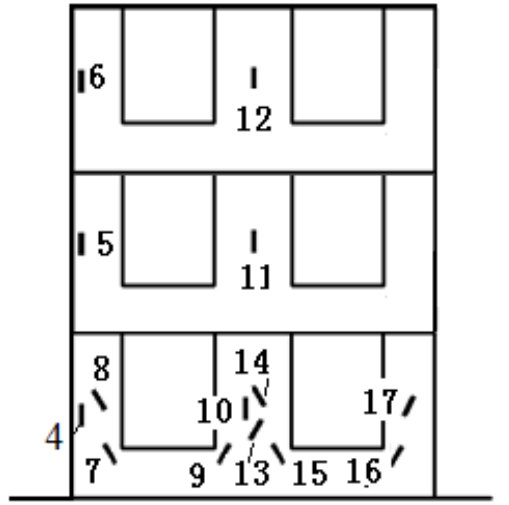

(a) outer longitudinal wall

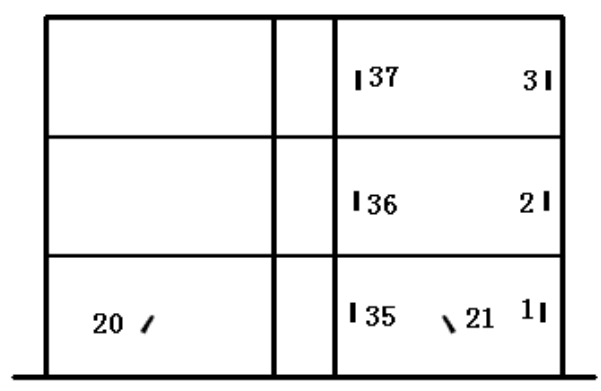

(c) Outer cross wall

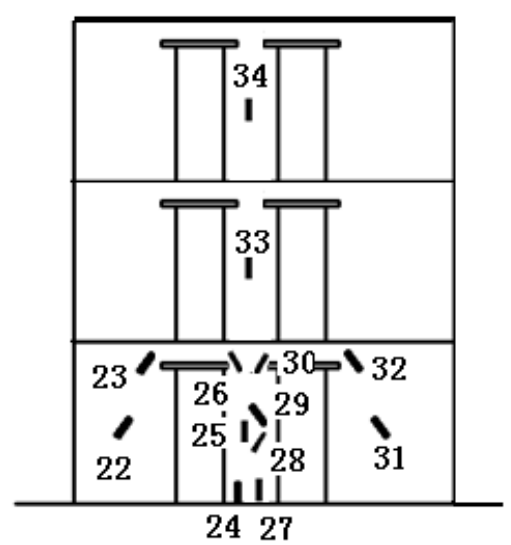

(b) Inner longitudinal wall

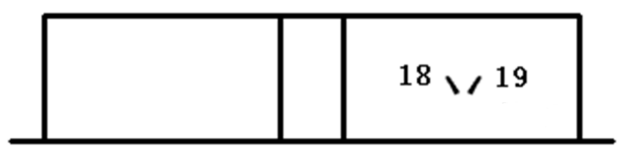

(d) Inner cross wall on the first floor

Fig. 3 The arrangement of strain gauges

\section{Ground motions}

Because of the similar ground motion adjustment, the time similiar constant is 0.5 , the acceleration similar constant is 1.15 , and the peak value of design ground motion before adjustment and after adjustment are shown in the Table 3.

Table 3 Adjustment of acceleration peak

\begin{tabular}{cccccc}
\hline Peak value of ground motion & \multicolumn{5}{c}{ Peak acceleration $(\mathrm{g})$} \\
\hline Design ground motion & 0.10 & 0.20 & 0.40 & 0.60 & 0.80 \\
Ground motion after ajustment & 0.12 & 0.23 & 0.46 & 0.69 & 0.92 \\
\hline
\end{tabular}

In the test, three ground motion was seleceted, which are El Centro, Taft and Wolong motion, whose information are shown in the Table 4, and the seismic curves are shown in Fig. 4-6.

Table 4 Ground motion information

\begin{tabular}{ccc}
\hline Ground motions & Site & Duration(s) \\
\hline El Centro & II & 53.8 \\
Taft & II & 65.0 \\
Wolong & II & 67.0 \\
\hline
\end{tabular}




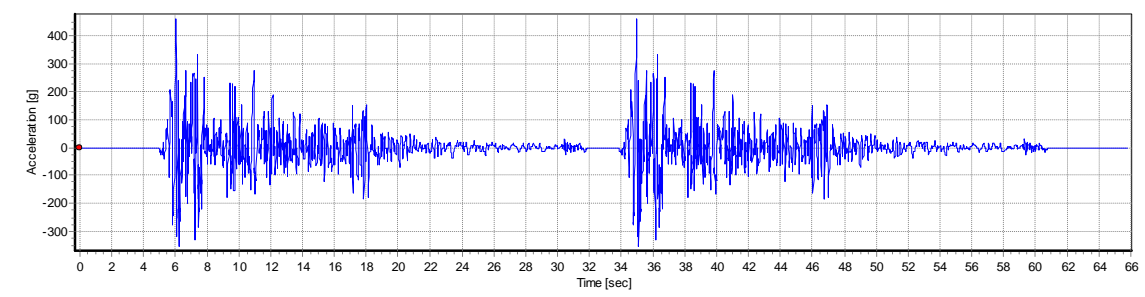

Fig. 4 El Centro ground motion time history curve

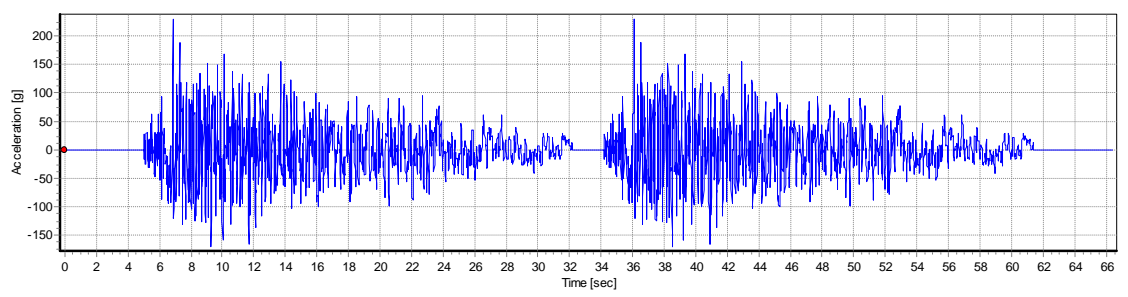

Fig. 5 Taft ground motion time history curve

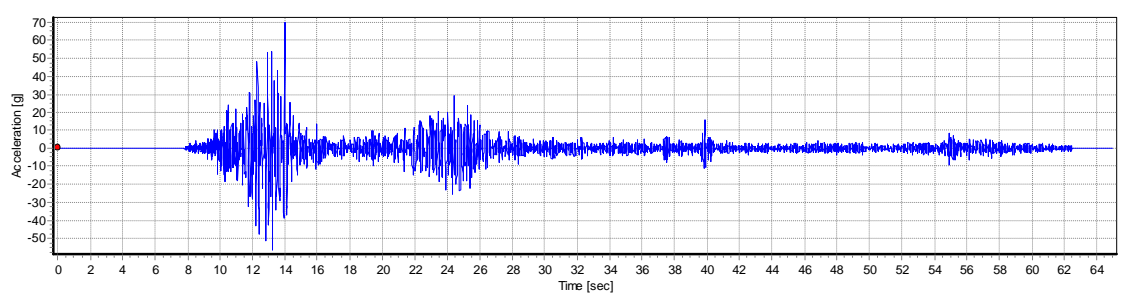

Fig. 6 Wolong ground motion time history curve

\section{Summary}

The 1:4 scale model for shaking table test was designed as a typical three-storey-office building in 1970's as a prototype with references to the earlier seismic code, and strengthened with external steel reinforcement mesh mortar layer. The first and second storey was strengthened and the third storey was untouched as comparison. The key techniques of the process of modeling were discussed, especially the determination of brick dimension and the co-working of the three different kinds of material, i.e. reinforcement mesh, mortar layer and brick wall. The selection of model material, the determination of similitude relationship, the construction methods of details of seismic measure and reinforcement layer were presented. The realizing way of structural members and the details of seismic measures were described in detail. The scheme of shaking table test was determined, including simulation of wall vertical compressive stress, the artificial mass, the distribution of test instrument and strain gauge, the selection of ground motions and the testing conditions.

\section{Acknowledgements}

This study is financially supported by NSFC with grant No. 91315301.

\section{References}

[1] Professional Standard of the People's Republic of China. GB50023-2009 Standard for seismic appraisal of buildings [S]. Beijing: China Architecture and Building Press, (2009) (in Chinese)

[2] Professional Standard of the People's Republic of China. GB50011-2010 Code for seismic design of buildings [S]. Beijing: China Architecture and Building Press, (2009) (in Chinese)

[3] Zhang Minzheng, Meng Qingli, Liu Xiaoming. Study on Shaking Table Test of Buildings [J]. Engineering Seismic. 2003, (04): 31-35. (in Chinese) 
[4] Jiang Lu, Li Xu, Ma Renle. Shaking Table Test Scaled Model Design for a Four-story School Building inMasonry Structure with Precast Slabs [J]. Journal of Sijiazhuang Tiedao University (Natural Science), 2011, 24(02):15-19. (in Chinese)

[5] Zhang Minzheng. Study on Similitude Laws for Shaking Table Tests [J]. Earthquake Engineering and Engineering Vibration, 1997, 17(02):52-58. (in Chinese) 